\title{
REFLEXÕES SOBRE OS DESDOBRAMENTOS ONTOLÓGICOS DA OBRA DE KAREN BLIXEN: minha fazenda na África *
}

\author{
REFLECTIONS ON THE ONTOLOGICAL RAMIFICATIONS \\ OF THE ART OF KAREN BLIXEN: out of Africa
}

\author{
REFLEXIONES SOBRE LAS RAMIFICACIONES ONTOLÓGICAS \\ DE LA OBRA DE KAREN BLIXEN: mi hacienda en África
}

Priscila Marchiori Dal Gallo

\begin{abstract}
Resumo: A literatura pode ser entendida como uma expressão poética e lírica das vivências e experiências do escritor. Dentro desse contexto, a escrita se figura como uma possibilidade de autocompreensão e de reflexões diante de questões humanas universais. A literatura desvela o Ser, não só do autor, mas também o Ser humano. Buscamos pensar sobre tal entendimento da literatura na obra de Isak Dinesen: Minha Fazenda na África. Para tanto exploramos e refletimos no presente texto as conexões entre: escritor e obra; leitor e obra; escritor-leitor-obra para assim avançarmos mais especificamente para as ponderações a respeito das conexões entre a escrita de Isak Dinesen e as experiências de Karen Blixen. Pelas vias do tom autobiográfico de Minha Fazenda na África, entrecruzamos a escritora e seu pseudônimo de modo a desvendar as motivações, anseios, devaneios e escapismos que estão envolvidos no ato de criação literária de Karen e que desvelam o sentido ontológico de sua escrita.
\end{abstract}

Palavras-chave: Literatura. Experiência. Escapismo.

\begin{abstract}
Literature can be understood as a poetical and lyric expression of the experiences of the writer. Inside of this context, the writing configures itself as a possibility of self-understanding and reflections in front of questions of universal human beings. Literature reveals the Being, not only of the author, but also the Human being. We seek to think about such understanding of the literature on the work of Isak Dinesen: Out of Africa. In order to do so we explore and reflect in the present text about the connections between: writer and work; reader and work; writer-reader-work thus to advance more specifically for the considerations regarding the connections between the writing of Isak Dinesen and the experiences of Karen Blixen. Through the autobiographical tone of Out of Africa, we intercross the writer and its pseudonym in order to unmask the motivations, desires, dreams and escapisms that are involved in the act of Karen' literary creation which unveil the ontological sense of her writing.
\end{abstract}

Keywords: Literature. Experience. Escapism.

Resumen: La literatura puede ser entendida como una expresión poética y lírica de las vivencias y experiencias del escritor. Dentro de este contexto, la escritura se presenta como una posibilidad de autocomprensión y de las reflexiones delante de las preguntas universales de los seres humanos. La literatura revela el Ser, no sólo del autor, sino también del Ser humano. Tratamos de pensar en esa comprensión de la literatura en la obra de Isak Dinesen: mi hacienda en África. De tal manera exploramos y reflejamos en este texto sobre las conexiones: escritor y obra; lector y obra; escritor-lector-obra y así a avanzar más específicamente para las consideraciones con respecto a las conexiones entre la escritura de Isak Dinesen y las experiencias de Karen Blixen. A través del tono autobiográfico de Memorias de África, entrecruzamos el escritor y su seudónimo para desenmascarar las motivaciones, los deseos, los sueños y los escapismos que intervienen en el acto de la creación literaria de Karen y que devela el sentido ontológico de su escritura.

Palabras clave: Literatura. Experiencia. Escapismo.

\section{PRIMEIROS PASSOS:}

a descoberta da obra

Não sabemos o que um livro irá nos trazer (seja bom ou ruim) até a sua última linha, até o último fôlego da última palavra. A cada linha brota uma experiência (estética) que se a princípio teve impulso pela (simples) curiosidade, agora é um mergulho e reverbera (no espírito) com sua intensidade. A literatura desperta reflexões...

A obra Minha Fazenda na África, de Isak Dinesen pseudônimo de Karen Blixen (escri-

\footnotetext{
*Artigo recebido em outubro 2012

Aprovado em dezembro 2012
} 
tora dinamarquesa) a princípio foi concebida como um relato das experiências no continente africano que tratava de maneira lírica suas paisagens e lugares a partir de descobertas e encontros da autora. Tais elementos trariam uma especificidade espaço-temporal bastante distinta: a impressão de uma grafia (africana) originada por relações homem-meio específicas e vista sob a perspectiva e intencionalidade de Karen. Com surpresa no desenvolver da escrita, a narrativa ganha profundidade tratando-se de um caminhar para o desvelamento do ser (de Karen), uma narrativa em que permeiam os anseios por descortinar (para si) sua forma de ser-e-estar-no-mundo.

$\mathrm{Na}$ narrativa pululavam vivências de expansão, amplitude e evasão (buscas imanentes à Karen Blixen) que gestam no texto desdobramentos ontológicos em um movimento de abertura do Eu de Karen, em sua questão mais premente: poder ser ela mesma consigo mesma. Esse movimento se firma na escrita de Karen (o seu Eu constituído na narrativa) e se torna presente e vigente na sinergia leitor-obra (escritor). Em sinergia com a obra, em um processo co-criativo, o leitor adentra o ato essencial (imanente) da obra de presentificar e desvelar questões primevas ao homem: nesse caso a organicidade da sua relação com o mundo e de que ser é ser em relação com. Nessa sinergia se desvela uma unidade, dentro de uma diversidade de existências, isto é, todos têm, por diferentes que sejam, questões para as quais se converge. A obra (narrativa) vem explicitar e clarificar esse processo. Mas antes de tudo a obra é a realização do ser escritor, em seu sentido mais imediato (de escrever) e no sentido existencial de habitar a linguagem entendendo e constituindo seu ser (relacional) no mundo. Esse é o ponto chave do presente texto: refletir como a obra de Isak Dinesen pode (espontaneamente) desvelar o ser da escrita e do escritor.

\section{SINERGIA ESCRITOR, LEITOR E}

LITERATURA: uma confluência imaginativa?

Vamos supor que nós sonhamos, ou inventamos,
aquilo tudo - árvores, relva, sol, lua, estrelas e até
Aslam. Vamos supor que sonhamos: ora, nesse caso,
as coisas inventadas parecem um bocado mais im-
portantes do que as coisas reais. Vamos supor então
que esta fossa. Este seu reino, seja o único mundo
existente. Pois, para mim, o seu mundo não basta. E
vale muito pouco. (LEWIS, 2009, p. 598)

Buttimer (1980, p. 1) coloca a necessidade de conceber os lugares em dois movimen- tos recíprocos: uma expansão para além dele (em busca do desconhecido) e o regresso a ele (ao familiar). A amplitude desses movimentos esquadrinha janelas. E nenhuma janela nos parece ser mais vasta e mais possível que a nossa imaginação. Como afirma Tuan (1990) todos os humanos possuem e são capazes de usar a sua imaginação. Essa é uma grande cúmplice de nossa pulsão evasiva e aventureira. O emergir de nossa natureza irrequieta se manifesta sempre diante do convite literário, para uma viagem literária. O texto literário, segundo Todorov (2009), é capaz de ampliar nossos horizontes incitando-nos a imaginar e experienciar outras formas de construção de nossa realidade imediata. Por vezes para além daquilo que concebemos como real e, assim, adentramos o fantástico e o ficcional. Essa é uma grande potencialidade da literatura, ela não tem o dever de revelar e representar a verdade. Ela se permite criar.

A literatura permite alcançar uma amplitude interior, na medida em que gesta e significa as diferentes possibilidades de real e de mundo. Podemos pensar que os lugares, em especial, a casa são o reino de liberdade, sendo sinônimos de liberdade. Eles são o substrato primeiro para o indivíduo poder ser em sua plena identidade (ser eu mesmo comigo mesmo). Contudo, a liberdade só pode se realizar como tal se existir concomitantemente a uma força de deriva e divergência. Que significa? Os lugares só podem ser o reino de liberdade se não aprisionam o indivíduo na monotonia da essencialidade identitária. Essa sim a pior e mais difícil de escapar, pois trata-se da monotonia de um ciclo infinito de repetições. O passado que se repete no presente em formas de hábitos e o futuro que será, previsivelmente, uma extensão do presente, que então, já será passado. Pocock (1988), citando Meing, traz a noção de "claustrofobia do ser" e a necessidade de uma amplitude da realidade externa para nosso bem estar. Em vista de fugir desta espiral de repetições nos lançamos a uma exterioridade, embarcada na imaginação. Eis que o convite literário oferece a oportunidade de deriva.

Enquanto leitor podemos nos personificar em uma personagem e nos redescobrir enquanto seres humanos em todas as ramificações de nosso ser ou podemos seguir os passos de alguém inteiramente diferente pela curiosidade de "e se eu fosse...". Os personagens podem se tornar companheiros indispensáveis, segundo Todorov (2009), em 
nossa descoberta do sentido de ser humano e do mundo. O importante é que em ambos os casos podemos experienciar existências e espaços alternativos, em toda a sua complexidade de sentimentos, ações e relações. A literatura permite reconhecer as várias facetas e maneiras do ser-aí, pois nos permite explorar a intimidade da relação homem-mundo em diferentes "aí" (construções literárias do espaço) e diversos "ser".

O texto literário é a criação de um mundo densamente texturizado (TUAN, 1978). A literatura é capaz, assim, de não só reconstituir experiências (em toda a intimidade de sentimentos da personagem), mas de criá-las em um conjunto de espacialidade e temporalidade auto-suficiente (POCOCK, 1988). Essas estão encaixadas, e ao mesmo tempo, distorcidas de nossa realidade imediata. Perscrutamos os caminhos da personagem (que compartilhamos com o autor) e como observador-participante da tessitura desse outro mundo experienciamos uma geograficidade literária: relação sujeito(personagem)-mundo(literário) (DAL GALLO; MARANDOLA JR., 2010).

Eis o maior convite e maior desafio da literatura. Como um mundo completo nele mesmo, o texto literário é um fluxo (finito) no qual o leitor deve adentrar para apreendê-lo por completo e poder senti-lo, vê-lo, respirá-lo. Sua complexidade consiste na destreza em que conseguimos participar da construção desse mundo (fluxo), a existência das personagens espelhando nela nossas experiências. O envolvimento com uma obra literária exige uma apreensão de diferentes níveis de realidade que são internos à própria obra (o autobiográfico, o fantasioso, o verossímil, o imaginado), como fala Calvino (1997). O ato da leitura é uma disposição em adentrar e nos harmonizar com essa tessitura, como coloca Oliveira Jr. (2010): todos os livros são mundos autoconsistentes criados pelo escritor, mas todos podemos como leitores fundar nosso próprio mundo em suas entrelinhas.

O texto literário atende às nossas expectativas e inquietude nos espraiando caminhos, cheios de intencionalidade, maquinações e conduções, mas prenhes de aberturas às possibilidades de criação. E criar é uma permissão à fuga. Enquanto estamos absortos às palavras, criamos uma abertura para transfigurar a realidade imediata e corrermos em paralelo a ela. Em outras palavras, o texto literário em seu constructo desafia uma ideia da realização humana constrangida e circunscrita a um lugar, um desafio à certeza (segurança) (POCOCK, 1988). Ele é extremamente atraente para borrar certos limites referentes às possíveis lógicas que regem nossa realidade. Ele tem um potencial para explorarmos as derivas identitárias e aos voos imaginativos pela variação de texturas que nosso mundo adota e as suas manifestações fantásticas em nossas criações imaginativas. O texto literário é um percurso criativo e imaginativo e como tal incita a viagem, uma viagem literária por um espaço, como aponta Oliveira Jr. (2010), do mundo imaginal; um espaço que se formula na reverberação das palavras no leitor.

A viagem literária é uma técnica de cuidado da alma (TODOROV, 2009). O autor convida a preenchê-la com uma experiência estética que torna o mundo mais pleno de significado e, por vezes, mais belo. O texto literário é seu intermédio e a sua possibilidade está na ressonância da leitura em cada leitor.

Quando aceitamos o convite à viagem proposta nos textos literários podemos nos perguntar o que impele o escritor a lançar o convite para transgredir a nossa realidade, fazendo ecoar suas experiências em nós?

Para entendermos essa pergunta, antes temos que entender a relação do autor com a sua própria obra. Tudo faz parte de um mesmo movimento. $O$ autor escreve desejando interlocução e nesse percurso ele precisa meditar sobre a sua relação (psicológica, literária, existencial) com esse mundo (de palavras) que ele está gestando. O escritor é fundador de uma nova geografia, que havia permanecido em seu âmago como uma terrae incognitae e que emerge como uma manifestação literária. A experiência da realização dessa manifestação permite que ele entenda sua relação com o mundo, ou que possa demonstrar suas amarguras e/ou felicidades perante sua realidade. Os leitores desbravam essa terrae incognitae e percorrem guiados literariamente um percurso de embrenhamento "nas florestas e selvas de nossas vidas" (OLIVEIRA JR., 2010, p. 106).

Bellemin-Noël (1983) faz a pergunta: o que o escritor lê quando escreve? E a responde dizendo que esse antes de tudo o lê ele mesmo. No ato da escrita o escritor tem um domínio (intelectual) sobre a narrativa que concede dar coerência e organização a suas experiências, bem como vivenciar novas outras. O autor tem a habilidade de descrever e manipular o tempo e o espaço de forma bastante perspicaz, a eloquência de sua narrativa Ihe dá uma coesão interna ao texto (que é diferente do verdadeiro ou da 
representação da realidade) necessária para legitimar a criação de seu mundo. E mais nos faz acreditar na sua existência (em si mesmo, não como parte de nossa realidade). O Eu do autor se confunde com a narrativa, e nela ele pode realizar aquilo que o real não the permite ou ele permite ao real ganhar novas configurações. Nesse sentido, o escritor lança, primeiramente, a ele mesmo o convite a uma viagem e a sua interlocução com os leitores permitirá que esses como ele realizem essa viagem.

Há um êxtase do próprio autor na e pela sua narrativa e pela sua própria viagem literária. Tuan (1990) afirma que não há primazia do realismo ou da fantasia para entender as pessoas e a realidade humana, ambos são os lados da mesma moeda e permitem explorar a natureza humana. Ele questiona se nossa simpatia pelos contos de fada e lendas não está fundada na impossibilidade de os separarmos rigidamente do real. O texto literário é uma interface entre diferentes níveis de realidade sua leitura é um percurso que nos distancia do real (imediato). Nele as palavras são providas de uma consciência literária compromissada com o imaginativo (CALVINO, 1997), mas o universo do texto mantém um contato verossímil com o universo do real. O texto literário transcende a dualidade real e imaginário/fantástico os reunindo dentro de sua própria lógica e com proximidades variáveis entre eles.

O importante é entender que essa reunião nasce em sua essência no amálgama da exterioridade e interioridade do escritor. Em seus textos, como afirma Tuan (1978), os escritores balanceiam as realidades subjetivas e objetivas. O texto literário expressa os meandros íntimos e internos do autor em uma espacialidade (estética) que se origina na necessidade do autor comunicar aspectos da condição humana e de nosso mundo que o chamaram a uma transformação interior, a uma experiência singular. O mundo escrito desse autor irá transbordar esse aspecto e subsidiará a sua plena vivência nos convocando a interagir com ele.

O texto literário ainda que autoconsistente, nunca está completamente encerrado e completo nele mesmo. Ele existe em uma relação de interlocução com o leitor, porque é dele que as palavras ganham sua substância, significado e organização espacial. Segundo Fluck (1999, p. 38, tradução nossa), "ao ler um texto literário, os personagens assim como as descrições do espaço retêm uma dimensão de indeterminação que tem que ser supera- da pelo leitor por meio da imaginação" ${ }^{\prime}$. A capacidade imaginativa do leitor, invocada pelo texto, é o que dá cor, forma, cheiro, textura ao mundo escrito, ou é a imaginação (em sua invocação das experiências do mundo) do leitor que será o âmago da factualização do texto literário. O leitor é aquilo que anima as palavras, a narrativa.

Por isso é essencial à destreza em relacionar o subjetivo e o objetivo. Para que a interlocução ocorra com os leitores, é necessário que a experiência particular possa alcançar uma universalidade como uma questão humana. Como coloca Calvino (1997, p. 114 tradução nossa), "o autor-protagonista traz uma internalidade subjetiva para o mundo escrito [...] a qual dimensiona a imaginação do leitor e age como um artifício conector de diferentes níveis da realidade" ${ }^{\prime 2}$. A singularidade da experiência (literária, estética, geográfica, imaginativa) composta pelo autor, precisa ser transversal para ser coletiva. É dessa maneira que se pode, enquanto leitor, compartilhar as experiências em tempos e terras distantes dos exploradores e viajantes, as experiências em mundos fantásticos ou fictícios de séculos futuros, as experiências da utopia, as experiências autobiográficas.

Nesse sentido, é possível entender a concepção de uma narrativa autobiográfica como Out of Africa ("Minha Fazenda na África" em sua versão brasileira) de Isak Dinesen. Centrado num relato sobre vivencias África (no período de colonização), o romance é um percurso autobiográfico ensejado em questões existenciais que perpassam frustrações, inseguranças, expectativas, devaneios e deleites. Isak Dinesen se apresenta em diversas facetas nesse percurso particular tranversalizando questões íntimas de sua condição humana. Isak Dinesen nos convida a uma viagem pelas terras imaculadas da África, nos ausenta de nossa realidade imediata, para proporcionar uma experiência (estética) reveladora dos inquietamentos de uma existência deslocada de seu tempo e espaço.

\section{EXPLORANDO OS MEANDROS DA ESCRITA DE KAREN BLIXEN:} uma constituição identitária

A situação geográfica e a altitude combinavamse para criar uma paisagem que não tinha igual no mundo. Não havia ali nada que fosse supérfluo ou Iuxuriante; era a África destilada através de dois mil metros de altitude, perfazendo a forte e refinada essência de um continente (DINESEN, 1986, p. 9) 
Nessa passagem de Out of Africa ou Minha Fazenda na África, Dinesen faz uma confissão de seu amor pela África e por sua fazenda aos pés das montanhas Ngong. Dinesen é atraída e se torna absorta na e pela geopoética de um "mundo colorido no qual ainda estavam presentes os vestígios de suas origens" (HENRIKSEN, 1967, p. 323, tradução nossa) . O esplendor das terras de sua fazenda se manifesta, para Dinensen, antes de qualquer espetáculo das paisagens e imagens. O esplendor está na ressonância entre a liberdade, o ritmo e a naturalidade do continente (e de seus habitantes) com suas próprias aspirações existenciais. A poética do continente Africano conseguiu cativar o âmago de Dinesen: "Lá, naquelas altitudes, respirava-se com facilidade, inalando segurança vital e leveza de coração. Nos altiplanos, acordava-se de manhã e pensava-se: 'Aqui estou, onde devia estar'" (DINESEN, 1986, p. 10).

Minha fazenda na África tem um forte tom autobiográfico. Sob o pseudônimo de Isak Dinesen, Karen Blixen escreve sobre o período de sua vida em que morou na África como uma proprietária de terras produtora de café. Diferente de seus conterrâneos europeus, ela teve uma vivência distinta das terras africanas, desenvolvendo um apego íntimo pelo continente e o mundo dos nativos africanos, os kikuyus. A trama do livro é um relato experiencial de Karen que transborda sua afeição e ligação (telúrica) às terras africanas e sua admiração pela condução da vida dos kikuyus, "A descoberta das raças escuras representou para mim um magnífico alargamento de meu mundo" (DINESEN, 1986, p. 21).

Apesar dos encantos de sua vida na fazenda, a admiração de Karen pela África estava para além de sua extensa plantação de café "com seu brilhante verde-vivo" (DINESEN, 1986, p. 12) e a "radiante visão da plantação em flor [...] como uma nuvem de giz em meio a névoa" (DINESEN, 1986, p. 13). Os safáris eram momentos de especial deleite para Karen. As recordações de suas incursões na África eram, agradavelmente, lembradas nos momentos em que não havia atividades na fazenda. Os safáris ganhavam o ar de sua graça por propiciar uma ligação íntima com o ambiente, o caçador deve se adaptar "aos ventos e às cores e cheiros do ambiente, fazendo com que o tempo próprio desse conjunto se torne o seu." (DINESEN, 1986, p. 20) em um encontro com tudo aquilo que é fundamentalmente diferente de suas coisas próprias. Descrições vívidas e intensas dos safáris são realizadas ao longo do livro, nelas as apreensões do encontro com o selvagem são objeto de fascínio.

A superioridade independente que Karen podia sentir do selvagem (em sua fazenda e seus safáris), pela sua resistência às formas de controle (físicas ou ideológicas) e a entrega as forças do destino e assaltos do incerto se transfiguram em uma liberdade e espontaneidade físico-mental ansiada longamente por ela de modo que "na negritude da África apenas Karen Blixen parece ter encontrado uma elevada e sonora resposta" (HENRIKSEN, 1967 , p. 326, tradução nossa) ${ }^{4}$. A ansiedade de Karen por essa resposta tem raízes num sentimento de solidão e deslocamento em relação à sociedade europeia, em especial a dinamarquesa, e uma nostalgia em relação a um tempo remoto da nobreza, que havia se esvanecido e se tornado invisível. Mesmo na África Karen teve forte sentimento de distanciamento do círculo social europeu com que tinha contato em suas idas a Nairobi, uma cidade a poucos quilômetros de sua fazenda. Sua vida é preenchida apenas quando está entre o povo Kikuyu": "quando ela se rendeu e entregou-se ao ritmo do mundo negro, foi quando ela veio a ser" (HENRIKSEN, 1967, p. 325, tradução nossa) $)^{6}$.

Contudo, Karen não encontrou plenamente seu lugar na África. No percurso de sua viagem de resgate à satisfação e realização (lírica) de estar na África, em seu texto literário, Karen Blixen deixa notas de um tédio e uma solitude profundos como na seguinte passagem: "Em certas ocasiões, a vida na fazenda se tornava extremamente solitária; na imobilidade das noites, quando os minutos pingavam do relógio, a vida parecia estar também se esvaindo de nós aos pingos" (DINESEN, 1986, p. 23). Essa angústia de Karen só era aliviada quando ela se ocupava em escrever histórias que levassem sua mente para lugares longínquos. Esse hábito tomou tal importância para Karen que ela o utilizava como válvula de fuga para diversas situações, principalmente concernentes a decisões de administração da fazenda, "A princípio eu escrevia apenas à noite, mas mais tarde frequentemente me sentava à mesa também, de manhã, quando devia estar lá fora na fazenda" (DINESEN, 1986, p. 44).

O prazer de Karen em criar histórias tornava os momentos de escrita naqueles de maior tranquilidade ontológica. Neles residia a possibilidade de uma fuga intensiva em suas viagens 
literárias. Sua realização ontológica era um acontecer intermediado pela literatura, a qual permitia transcender a dualidade interno-externo. Como coloca Antonello (2010), a criação literária é uma reelaboração da realidade em que convergem os planos objetivo e subjetivo, que germina uma construção cujo substrato são as volições e predileções do autor. Karen se realiza em seu poder absoluto sobre o destino e criação que lhe proporcionam uma agradável evasão "Um mundo criado pela sua arte, onde é possível para uma personagem desempenhar um papel aceitável e ordenado" (HANNAH, 1963, p. 589, tradução nossa) ${ }^{7}$.

Podemos presenciar um processo de fuga (intensiva) de Karen para o interior de suas narrativas. Em sua escrita ela cria aquilo que Takolander (2009) chama de metáfora espacial. Karen cria um espaço literário em que a realidade imediata se transforma em uma experiência literária e estética, em que prepondera a imaginação. O espaço da linguagem (uma metáfora da realidade) transporta Karen para um mundo em que ela pode dominar e superar seus anseios colocados a sua condição humana. A virtude de Karen de ser uma contadora de histórias, alguém que domina a linguagem, permite a ela trafegar pelo simbólico se abstendo de manter-se conectada à concretude. Seu espaço metafórico não precisa ser justificado como uma representação do real, ele se legitima nele mesmo. A arte não está enraizada numa representatividade verdadeira do real, ela tem a liberdade de redefinir e transformar a realidade ou mesmo de inventá-la (FLUCK, 1999).

No romance Minha Fazenda na África há uma densa sobreposição de "Eus", como afirma Calvino (1997, p. 111, tradução nossa), "É sempre uma projeção de si mesmo que o autor envolve enquanto ele está escrevendo; essa pode ser uma projeção de seu Eu real ou a projeção de um "Eu" fictício"8. Existem sucessivas camadas de subjetividade no romance que amalgamam Isak Dinesen e Karen Blixen em uma continuidade descontínua de experiências. Karen pode conceber um mundo em que pode deturpar a realidade em favor da concretização de suas expectativas. Esse é o poder da literatura para Karen.

O convite literário que Karen Blixen faz em Minha fazenda na África é uma experiência estética em que se aflora ao leitor os meandros da escrita (da escritora). Se pudermos nos libertar das amarras da atividade intelectual (racionalização) e confiarmos em algo mais fluido, entregando à nossa intuição a cocriação do mundo escrito por Karen, podemos caminhar por suas entre linhas e descobrir a beleza do não visto.

Karen é a sua primeira espectadora (espectadora de si mesma), ela experiencia em sua criação a sua condição humana. Sua escrita é a experiência da sensibilidade, um encontro com a poética e lírica que Karen sentia ao olhar o horizonte, ao ver as crianças kikuyus, ao presenciar a força selvagem. E a poética de sua solitude e seu pesar. Um amigo de Karen, ainda na África, disse a ela: "a vida nunca fará uma melodia para sua dança" (HENRIKSEN, 1967 , p. 319, tradução nossa) . Uma passagem em que Karen faz um relato intenso de seu deslocamento do mundo é uma caçada de três leões. Ela glorifica o risco da morte "Venha - eu the disse -, vamos arriscar nossas vidas desnecessariamente. Pois se nossa vida tem algum valor, então é precisamente este: não tem valor nenhum. Frei lebt wer sterben kann ${ }^{10}$." (DINESEN, 1986, p. 206).

O leitor participando das vivências de Karen em seu romance alcança uma questão essencial nas entrelinhas de seu texto: uma intensa topofobia sentida pela autora em relação a sua terra natal, isto é, a Dinamarca. Um lugar ao qual ela nunca se sentiu pertencente. A sua viagem literária (pela África) é a expressão de uma impulsão pela fuga fomentada por uma questão existencial: na Dinamarca Karen não podia ser ela mesma consigo mesma. Essa dissonância existencial cria uma melancolia com limites numa perda da pulsão da vida. E isso se sente quando na sua partida da África, frente às dificuldades financeiras geradas por crises na produção de sua fazenda, Karen sente-se "como um fantasma, que, segundo dizem, apenas caminha e caminha, sem qualquer definição quanto a por quê e para onde" (DINESEN 1986 , p. 283). Mas acima de tudo ela haveria de voltar para a Dinamarca, terra que havia deixado, esperando que para sempre.

Em seu retorno para a Dinamarca Karen Blixen escreveria um acervo de obras renomadas como: Seven Gothic Tales (Sete Contos Góticos), Winter's Tales (Contos de Inverno); The Angelic Avengers (As Vingadoras Angélicas); Last Tales (Últimos Contos); Anectodes of Destiny (Anedotas do Destino) que a alçaram como uma escritora bastante influente, na Europa (fora da Dinamarca, e sobretudo, nos Estados Unidos, onde obteve o primeiro lugar nas vendas) diversas vezes no círculo do livro do país. Para Karen a Dinamarca não 
conseguia acompanhar suas ironias e senso de humor, a força das construções literárias da autora não encontravam cúmplices e apreciadores. Esses foram muitos poucos.

O ambiente dinamarquês não era acolhedor a forma de perceber e se relacionar com o mundo de Karen, que acaba se reconhecendo e identificando nas incertezas e desvario africano. A incognoscibilidade da fala de Karen na Dinamarca (ruídos na intersubjetividade) e a surdez de Karen as vozes do seu país (incompreensão aos apelos daquela terra) criou uma relação hermética entre a escritora e seu país. A escritora se volta às suas vozes interiores e busca viver como uma imagem mitológica: da escritora emana a fantasmagoria de uma mulher (desejosa de grandezas) que "deixou um "verdadeiro eu", um eu inviolável e secreto, viver nas obras e na companhia dos autores, enquanto seu "falso eu", vago e flexível, satisfazia as demandas da existência monótona" (THURMAN, 1982, p.66). Esse eu envolto de sonhos e devaneios se avoluma em um misto de satisfação e imortalidade, e só pode ser protegido quando sacralizado o seu subsídio existencial: a literaridade (e o lírico) do mundo.

\section{A LIBERDADE DA CONTADORA DE HISTÓRIAS:}

o sacrifício ritual da vida pela arte

[...] quando havia aperfeiçoado a sua persona e quase nunca a abandonava (THURMAN, 1982, p.437)

O trecho acima se remete à construção de um casulo, quase impenetrável, que Karen Blixen se emprenhou por longo tempo em tecer como uma forma de proteção diante do silêncio que o seu país (onde não encontrava interlocutores), a Dinamarca, representava (para ela e para suas obras). Karen tinha a impressão que sua voz agia apenas em ecos em sua terra natal, sendo ela a única a ouvir sua própria voz. Em especial em meio a sua família, após a morte de seu pai, ao qual atribuía toda nostalgia de uma liberdade infantil, de poder ser ela mesma e não um elemento de uma irmandade, junto de suas duas irmãs, como passou a ser na juventude. Sua família impunha constrições moralista selecionando as condutas aceitáveis e harmônicas para com o desejo de distinção e castidade. Seu pai, completo oposto, era um viajante inveterado, quase um libertino e mostrou à sua filha a amplitude da vida em seus diversos sentidos. Com a sua morte, Karen perdeu essa liberdade e sua individualidade (identidade), sendo capaz apenas de retomá-las na África. Mas, sobretudo, retomá-las como uma contadora de histórias.

Karen transformou o seu ato de escrever e contar histórias em um ritual, em que a vida vai dando lugar à arte: "ela prometera sua alma ao Demônio em troca da promessa de que sua vida seria transformada em histórias" (THURMAN, 1982, p.444). Nesse movimento tudo que Karen enxerga é um distanciamento do mundo e um caminho para a solidão. 0 desejo de amparar a sua fragilidade diante do silêncio de sua terra natal a faz se recolher em si mesma e criar um escudo: a escrita. Esse movimento pode ser mais bem expresso pela seguinte passagem do conto $O$ Espelho de Machado de Assis:

\section{O sono dava-me alívio, não pela razão de ser irmão da morte, mas por outra. Acho que posso explicar assim esse fenômeno: - o sono, eliminando a neces- sidade de uma alma exterior, deixava atuar a alma interior. [...] quando acordava [...] a alma interior perdia a ação exclusiva, e ficava dependente da ou- tra. (ASSIS, 1992, p. 15)}

Para Karen escrever era como o sonho, que the permitia dar exclusividade a sua alma interior, e contraditoriamente, lhe permitia, como uma máscara, firmar a sua "alma exterior" como coloca o autor do conto: "cada criatura humana traz duas almas consigo: uma que olha de dentro para fora, outra que olha de fora para dentro..." (ASSIS, 1992, p.9). A alma exterior de Karen eram os seus ouvintes e leitores, que Ihe transmitiam alguma vida. Karen vela a sua alma exterior de forma a não perder metade de sua existência, e para isso ela fortifica sua persona, nunca a abandonando: "Seu próprio eu, sua personalidade e existência são refletidas no interior da mente de cada pessoa que você conhece e com a qual vive, com uma semelhança, uma caricatura de você mesmo, que ainda supõe viver, de certa forma, a verdade sobre você" (DINESEN, 1934 apud THURMAN, 1982, p. 420).

A alma exterior que a África era para Karen residia na concretude da montanha $\mathrm{Ngong}$, de seus campos de café, do povo Kikuyus, das armas e leões, do sol e o calor, foram evaporados dando lugar a uma alma exterior mais inconstante e efêmera: cortesia, respeito, admiração e a cocriação de seu mundo imagético. Quem poderia entendê-la, se não aqueles que compartilhavam suas histórias. Dar vida a suas histórias era manter acesa e vívida à alma exterior de Karen. Em outras palavras, ela existe em travessia e no intermédio: em 
permeio no mundo (material) e no mundo estético e imaginativo (imaterial).

A contadora de histórias criava um mundo, como uma ilha, nas fronteiras de seus sonhos de modo a elevar-se (as alturas) para além do cotidiano (o palco da vida cotidiana) a uma forma de arte. A literatura tinha o poder de transcender a realidade (imediata) reconciliando desejo e experiência, que de outro modo estariam em disputa irreconciliável. Viver por esse ato criativo: transformar tudo em história era a permuta da vida na arte. Karen aproximava as duas almas (interior e exterior) como aproximava a ficção da realidade, uma interface em que a sua psicologia e a literatura se fundiam. Estar em travessia dava forma a sua vida, isso Ihe faltava na concretude, suas histórias podiam começar com "um fato real, vivido, Mas isso era apenas um grão de poeira em volta do qual cresce a pérola. Não é importante, no fim nem é percebido" (GILLÈS, 1965 apud THURMAN, 1982 , p. 290).

As pérolas de Karen tinham uma constituição imortal, ela esforçou-se em fazê-las belas o bastante para atrair e seduzir de modo que de mãos em mãos elas manteriam a sua alva vitalidade. Os olhos que nelas posassem as revitalizariam, à sua própria maneira, as histórias eram imortais. E por assim ser, a elas, exclusivamente, Karen era capaz de libertar seu eu, a elas podia entregar a sua vida sem temer tê-la despedaçada (durante toda a vida tinha medo de amar espontaneamente, pelo risco da morte/perda). A segurança ontológica de Karen tinha seu reguardo em sua escrita, era ali que ela cultivava um habitar para o seu ser.

Suas construções literárias (habitar) não se reduziam à sua existência, em seus múltiplos níveis de realidade, Karen se diluía em aspectos, caráter, hábitos, palavras, valores. Há uma irredutibilidade da história a Karen e de Karen à história. A contadora de histórias estava inacessível e absorta (aos fragmentos) em suas criações líricas (estéticas). Suas criações eram para Karen o espelho do alferes, do conto O Espelho: "no fim de oito dias, deu-me na veneta de olhar para o espelho com o fim justamente de achar-me dois. [...] o vidro produziu então a figura integral; nenhuma linha de menos, nenhum contorno diverso; era eu mesmo, o alferes, que achava, enfim, a alma exterior." (ASSIS, 1992, p.16-18). Que mundo poderia ser a alma exterior de Karen, cuja profundidade e sensibilidade da alma Ihe era inata, adorava o lúdico e o imaginário, tão cúmplice e complementar quanto um mundo criado por ritualizações oníricas.

\section{5 À gUISA dE CONCLUSÃo}

Desdobram-se de nossa leitura de Isak Dinesen reflexões sobre o nosso (próprio) envolvimento com a literatura. Que nos faz buscar, no silêncio e introspecção da escrita, caminhos para descobrir uma amplitude interna? Nessa busca, cultivamos com afinco as possibilidades de conhecer-nos (com densidade) e nos propomos a embarcar em uma viagem com traços particulares e universais ao mesmo tempo.

Podemos conceber como resposta à questão uma urgência por uma forma de liberdade: existir como centro criador de si (ainda que atravessado por vontades implícitas à escrita). Essa liberdade é a de (re)inventarse, de sair de si e se expandir (estender-se no texto literário) e de trazer à tona imanências latentes pelas vias de uma empatia e cumplicidade com trama e as personagens da obra. Nesses termos aceitamos o convite para uma viagem literária, pelo devaneio e deriva que ela nos conduz, pelo frescor e as descobertas que proporciona.

Buscamos encontrar, ou pelo menos tatear através das viagens literárias, uma consciência do ser. O literário abre os fenômenos e proporciona sensações insubstituíveis transformadoras e reveladoras do ser. A literatura se figura como uma forma de nos retirar de uma queda ou imersão cotidiana de modo a alcançarmos uma compreensão da terrae incognitae: a intimidade ontológica. A escrita de Karen nos proporciona essa possibilidade.

Karen Blixen permeia as linhas de Minha Fazenda na África com a intensidade (sutil) de seus sentimentos e vivências, nostálgicas e ao mesmo tempo vibrantes, no continente africano. A escritora em seu romance proporciona uma experiência estética (sensível) e avoluma a complexidade da relação com o mundo, na medida em que intensifica o intercurso, entre internalidades e externalidades, dirigente de sua escrita. Na tessitura e enredo de sua obra se espraiam caminhos que são perpassados pela sua intencionalidade sim, mas que mesmo tratando de uma experiência singular e significativa para ela é capaz de conduzir a uma ampliação existencial (de forma intersubjetiva), porque nos toca e nos move.

Essa ampliação decorre por um lado pela força de suas memórias remetentes a exterioridades imaginativas vivas e inebriantes (o selvagem, a amplitude). Por outro lado pela capacidade da obra, como uma criação reflexiva (de si e para si), de abrir e desvelar os significados 
pelos quais as experiências (a vida) podem ser manifestadas. A escrita conduz a um ato interpretativo da existência, isolada das praticidades cotidianas, isto é, a escrita de Karen desvela o ser de seu ser. Como coloca Nunes (1999, p.146) "graças a escrita o mundo do texto pode explodir o mundo do autor".

$\mathrm{Na}$ escrita o ser está em aberto, porque na nervura das palavras habita a capacidade de expressão do ser. É através da criação literária que intersubjetivamente podem ser desfeitos os nós existenciais. O escritor abre o mundo e a si mesmo para si e para os leitores, interlocutores. Em outras palavras, a literatura é livre e dotada de profunda sensibilidade para reunir o ser à escrita. Isso só pode provir de uma compreensão profunda de como a escrita elucida os nexos de coexistência do ser com o mundo. Essa compreensão emerge de uma escrita em que o ser se doa com intensidade afetiva, quando viver se permuta em escrever.

Escrevo-te toda inteira e sinto um sabor em ser e o sabor-a-ti é abstrato como o instante. É também como o corpo todo que pinto os meus quadros na tela fixo o incorpóreo, eu corpo-a-corpo comigo mesma. Não se compreende música: ouve-se. Ouve-me então com o teu corpo inteiro. Quando vieres a me ler perguntarás por que não me restrinjo à pintura e às minhas exposições, já que escrevo tosco e sem ordem. É que agora sinto necessidade de palavras - e é novo para mim o que escrevo porque minha verdadeira palavra foi até agora intocada. A palavra é a minha quarta dimensão (LISPECTOR, 1998, p. 3, grifo nosso)

\section{NOTAS}

1. "in reading a literary text, characters as well as description of space retain a dimension of indeterminacy that has to be overcome by the reader through her own imagination"

2. "the author-protagonist bring an internal subjectivity to the written world $[\ldots]$ which sizes the imagination of the reader and acts as a device to connect the different levels of reality"

3. "colourful world which still bore trace of its origins"

4. "in the darkness of Africa only Karen Blixen seems to have found a great and sonorous response"

5. Os kikuyus é um grupo étnico africano muito presente no Quênia, país em que se localizava as terras de Karen. Muitos deles ocupavam terras próximas da fazenda e trafegavam por ela sem muitas restrições, alguns trabalhavam nas atividades de lavoura ou domésticas na fazenda.

6. "when she yielded and gave way to the rhythm of that dark world, it was then that she came into being"
7. "A world is created by her art, where it is possible for a character to play an accepted and ordained role"

8. "It is always only a projection of himself that an author calls into play while he is writing; it may be a projection of a real part of himself or the projection of a fictitious ' $I$ '"

9. "life will never make a tune for your dancing"

10. Vive livre quem pode morrer

\section{REFERÊNCIAS}

ANTONELLO, Ideni T. As territorialidades amazônicas reluzem na narrativa literária de Peregrino Júnior. In: MARANDOLA JR., Eduardo; GRATÃO, Lucia H. B. (Org.) Geografia e literatura: ensaios sobre geograficidade, poética e imaginação. Londrina: EDUEL, 2010.

ASSIS, Machado de. O espelho. In: RAMOS, Ricardo (Ed.). A palavra é... mistério. Ed. São Paulo: Scipione, 1992. p. 7-20.

BELLEMIN-NOËL, Jean. Psicanálise e literatura. São Paulo: Cultrix, 1983.

BUTTIMER, Anne. Home, reach, and the sense of place. In: BUTTIMER, Anne; SEAMON, David (Ed.). The human experience of space and place. London: Croom Helm, 1980.

CALVINO, Italo. The literature machine. London: Vintage, 1997.

DINESEN, Isak. Entre dois amores (a fazenda africana). São Paulo: Círculo do Livro S. A., 1986.

FLUCK, Winfried. Imaginary space: or, space as aesthetic object. In: BENESCH, Klaus; SCHMIDT, Kerstin (Ed.). Space in america: theory - history - culture. Amsterdam/New York: Editions Rodopi B.V, 2005.

GALLO, Priscila M. D.; MARANDOLA JR.

Eduardo. Ser e estar na cidade literária: as "Kyotos" de Kawabata. Caderno de Geografia, v.20, n.34, p.1-21, 2010.

HANNAH, Donald. Memoriam karen blixen: some aspects of her attitude to life. The Sewanee Review, v. 71, n. 4, p. 585-604, 1963.

HENRIKSEN, Aage. A portrait of Karen Blixen. Orbis Litterarum, v. 22, n. 1, p. 319-342, 1967.

LEWIS, Clive S. As crônicas de Nárnia. São Paulo: Martins Fontes, 2009.

LISPECTOR, Clarice. Água viva. Rio de Janeiro: Rocco, 1998. 
NUNES, Benedito. Hermenêutica e poesia: o pensamento poético. Belo Horizonte: Ed. UFMG, 1999.

OLIVEIRA JR., Wenceslao M. de. Rumo às entranhas - um percurso pelo rio até o coração da treva. In: MARANDOLA JR., Eduardo; GRATÃO, Lucia H. B. (Org.). Geografia e literatura: ensaios sobre geograficidade, poética e imaginação. Londrina: EDUEL, 2010. p. 99-119.

POCOCK, D. C. D. Geography and literature. Progress in human geography, v. 12, n. 1, p. 87-102, 1988.

TAKOLANDER, Maria. "Energetic space": the experience of literature and learning. College literatura, v. 36. n. 3, p. 165-183, 2009.
THURMAN, Judith. A vida de Isak Dinesen. Rio de Janeiro: Record, 1982.

TODOROV, Tzvetan. A literatura em perigo. Rio de Janeiro: Difel, 2009.

TUAN, Yi-Fu. Literature and geography: implications for geographical research. In: LEY, David; SAMUELS, Marwyn S. (Ed.). Humanistic geography: prospects and problems. Chicago: Maaroufa Press, 1978. p. 194-206.

Realism and fantasy in art, history, and geography. Annals of the Association of American Geographers, v. 80, n. 3, p. 435446, 1990. 